\title{
Formas de curanderismo en la Manchuela albacetense. Identidades y paradigmas ${ }^{1,2}$
}

\section{Folk Healing forms in the Manchuela of Albacete, Spain. Identities and Paradigms}

\author{
Jaime de las Heras Salord \\ Facultad de Medicina. Universidad de Castilla-La Mancha. Ciudad Real
}

\section{RESUMEN}

La práctica del curanderismo reviste aspectos muy distintos, vinculados al medio en el que se produce y a las relaciones sociales que lo estructuran. En este artículo se parte de los modelos descritos por Irwing Press, Eduardo Menéndez, Roberto Campos, Gerardo Fernández Juárez o Francisco Ferrándiz para tratar de articularlos con los resultados obtenidos en un trabajo de campo realizado en la Manchuela albacetense, comarca situada al norte de la provincia de Albacete en España. Se proponen dos categorías de curanderos — endo y exocuranderos- basadas en diversos elementos, como la construcción social del sanador, la naturaleza de su performance y el pago de sus servicios, entre otros. Esta dicotomía se reproduce en otros escenarios terapéuticos, como la medicina científica o la sanación por medios espirituales.

Palabras clave: Sanadores folk, Constructivismo, Castilla-La Mancha.

\section{SUMMARY}

The practice of curanderismo, or healing, takes very different forms according to the context in which it takes place and the social relationships supporting it. This article begins with the models described by Irwin Press, Eduardo Menéndez, Roberto Campos, Gerardo Fernández Juárez and Francisco Ferrándiz and seeks to express them in terms of the results obtained in field work carried out in la Manchuela, a region located in the north of the Spanish province of Albacete. We propose two categories of curanderos, endo- and exocuranderos-, based on various criteria such as, among others, the social construction of the healers, the nature of their performances and how their services are paid for. This dichotomy is also found in other therapeutic settings, such as scientific medicine or healing by spiritual means.

Key words: Folk healers, Constructivism, Castilla-La Mancha.

\footnotetext{
${ }^{1}$ Queremos manifestar nuestro agradecimiento a las personas de Casas de Juan Núñez que nos han transmitido las informaciones expuestas y analizadas en este artículo, que han autorizado su difusión mediante consentimiento informado.

${ }^{2}$ Una versión previa de esta investigación fue presentada a la European Social Science History Conference (ESSHC), celebrada en Glasgow, del 11 al 14 de Abril de 2012, como comunicación oral no publicada posteriormente.
} 


\section{INTRODUCCIÓN}

Una de las alternativas clásicas seguidas por la población a través de los itinerarios terapéuticos (Kleinman y Csordas 1996: 3-21) ${ }^{3}$ ha sido la consulta con el curandero ${ }^{4}$. Esta forma de asistencia ha sufrido cambios profundos en las últimas décadas, ligados a los procesos de urbanización y al éxodo rural. Hoy día podemos distinguir entre curanderos tradicionales y neocuranderos urbanos, sobre cuyos respectivos modos de actuar gravitan distintos paradigmas culturales. Así, la función estructuradora del grupo social, característica de las formas tradicionales de curanderismo, parece ser desplazada por una performance ritual con claros matices mercantiles en las formas de neocuranderismo urbano, hecho que recuerda la transición de la solidaridad de formas mecánicas a orgánicas (Durkheim 1995) en relación con el cambio social.

Los objetivos de este trabajo son dos, ambos en el plano del análisis cualitativo. El primero, describir la realidad de estos tipos de curanderismo en una localidad de Albacete (España) a lo largo de los últimos cuarenta años y analizar la relación entre ambos. El segundo, tratar de desvelar la relevancia de la propia comunidad en la construcción sociocultural de los sanadores folk. Se observa cómo, en relación con un proceso de transformación profunda del grupo social, han cambiado los mitos y creencias en torno a la salud en el sector folk, así como la propia imagen del curandero y sus relaciones con la comunidad. Se consideran, a este respecto, desde los planteamientos de Irwin Press (1971) hasta los postulados más recientes en torno al curanderismo utilizados por Eduardo Menéndez y Roberto Campos (1998) en México, por Gerardo Fernández Juárez $(2004,2008)$ en Bolivia y por Francisco Ferrándiz (2004) en Venezuela.

En cuanto a la metodología etnográfica se han seguido las orientaciones propuestas por Hammersley y Atkinson (2009), y Velasco y Díaz de Rada (2003) para la realización del trabajo de campo etnográfico. Así, se han utilizado cincuenta entrevistas semiestructuradas, realizadas desde octubre de 2010 hasta febrero de 2011, y otras informaciones obtenidas mediante la técnica de la observación participante sobre la población de Casas de Juan Núñez (Albacete). Este material, procedente de la tesis doctoral del autor (De las Heras Salord 2013), ha sido complementado con nuevas entrevistas orientadas hacia el estudio del curanderismo en esta población a lo largo de la historia.

\section{ACERCA DE LA NOCIÓN DE "MEDICINA POPULAR"}

La construcción del concepto de medicina popular, acuñado en el siglo XIX, se relaciona con la necesidad, por parte de las instancias religiosas y médico-científicas,

\footnotetext{
${ }^{3}$ Dichos autores definen el itinerario terapéutico como la secuencia de actuaciones que los pacientes o sus familiares ejecutan para afrontar la dolencia.

${ }^{4}$ Para una mayor aproximación a la realidad del curanderismo en España en los últimos veinte años véase Briones (1999), Gómez García (1994a y b), Erkoreka (1989, 2005), Reverte (1983), Devesa et al. (2005), González Alcantud y Rodríguez Becerra (1996), Fresquet et al. (2006), Fernández (1996) o Linares, Moral y García (2002). Un análisis de estas estrategias de sanación, en el contexto del pluralismo asistencial, puede consultarse en Perdiguero (2004b, 2006, 2009).
} 
de delimitar sus límites culturales y operativos (Comelles 1997: 247-280). Para Comelles el dispositivo colectivo de seguridad fue controlado hasta esa fecha por la religión cristiana, que había rechazado sistemáticamente las prácticas populares — supersticiones, reliquias, milagros - para garantizar su poder hegemónico en la sociedad.

El análisis de la evolución de este concepto ha sufrido distintos enfoques a lo largo del último siglo en los que se han plasmado intereses biomédicos, perspectivas antropológicas y planteamientos político-sociales. Así la medicina popular, inicialmente concebida como un conjunto de "errores y supersticiones" que, en aras de una práctica médica ortodoxa, convenía erradicar, pasó, ya en el siglo XX, a poseer un papel integrador en el grupo social y, posteriormente, a ser considerada una alternativa más en el itinerario terapéutico (Martínez Hernáez y Comelles 1994: 109-136). Erwin Ackerknecht diferenció entre medicina primitiva y popular. La primera constituiría un verdadero sistema médico, caracterizado por su naturaleza mágico-religiosa, su holismo y el tipo de mediador que interviene en la sanación —el hombre-medicina-y desempeñaría un papel social orientado a sustentar elementos morales (Ackerknetcht 1985: 21-29). Por su parte, la medicina popular sería una construcción elaborada a partir de medicina primitiva, galenismo y medicina científica (Ackerknecht 1985: 10).

En los años setenta aparecieron nuevas posturas que, desde la antropología, rebatían los modelos anteriores, concebidos a partir de perspectivas próximas a la biomedicina. Arthur Kleinman (1978: 86-87) propuso una estructura de sistemas de salud basada en las opciones que el individuo utiliza para afrontar la enfermedad, a las que denominó sectores e identificó como: sector popular, folk y profesional, existiendo con frecuencia solapamientos entre los tres. El sector folk estaría representado por sanadores no profesionales ${ }^{5}$. El camino seguido por el enfermo transitando a través de estos sectores configuraría el ya citado itinerario terapéutico.

\section{DE LOS CURANDEROS A LOS YATIRIS}

La figura del curandero ha pasado, a través de estas distintas lecturas de la realidad asistencial, de representar una impostura a tener una asignación por derecho propio en la escena del proceso salud/enfermedad/atención, aunque sigue constituyendo un cajón de sastre en el que cohabitan distintas representaciones, tanto de tipo religioso como secular, reunidas en ocasiones bajo el polémico término de "Medicina tradicional". Esta expresión adolece de un notable sesgo por su ahistoricidad y por el hecho de que, entre los sanadores no profesionales, se incluyen a menudo tanto los procedentes de sistemas médicos ajenos al biomédico como los derivados de él, teniendo todos ellos en común su carácter alternativo y de subordinación al modelo médico científico hegemónico a partir de procesos sociales, económicos e ideológicos (Menéndez 1992: 102-103).

Irving Press (1971: 741-756) describió un modo particular de curanderismo en la periferia de Bogotá, contrapuesto en su modelo teórico al del curanderismo rural o tribal, al que denominó "urban curanderismo complex", caracterizado por una gran

\footnotetext{
${ }^{5}$ A este grupo pertenecerían todos los curanderos, tanto los sancionados históricamente por la comunidad como los neocuranderos.
} 
heterogeneidad, tanto en su autodenominación, como en los modos de curar, en el tiempo dedicado a cada paciente o en la forma de cobrar por sus servicios. Esta noción expresa un tipo de curanderismo que surge para cubrir necesidades culturales de colectivos de tradición rural que emigraron a la periferia de las grandes ciudades (Granero Xiberta 1985: 379) y se caracteriza por una fuerte sistematización y una aproximación imitativa a las estrategias médico-científicas (Granero Xiberta 1987: 22).

Para Roberto Campos (1998: 11) existirían ocho niveles de terapeutas no profesionales: tres domésticos - hermana, madre y abuela - y cinco especializados: experta de vecindad, experto de barrio, curador urbano, curador regional y curador internacional. Entre los especializados ubica a chamanes — que caen en trances en los que se mantiene la voluntad-, parteras, bueseros y sobadores, yerbateros, espiritualistas, fidencistas, mediums y espiritistas ${ }^{6}$. En el curanderismo urbano se dan, según este autor, varias circunstancias: su uso por miembros de clases sociales subalternas, la fusión en sus prácticas de elementos consuetudinarios con saberes contemporáneos procedentes de otros sectores - particularmente del médico científico- y el uso real o supuesto de poderes mágico-religiosos. Su práctica no va dirigida únicamente al tratamiento y prevención de las enfermedades culturales ${ }^{7}$ sino que son elegidos por los segmentos más desfavorecidos de la población para el tratamiento de las más diversas patologías.

Determinadas orientaciones en el marco de los sanadores no profesionales y sus prácticas se generan a partir de la necesidad colectiva de buscar nuevas identidades, como acontece, por ejemplo, en la redefinición del culto venezolano a María Lionza (Ferrándiz 2004: 18). Para dicho autor en la performance de este ritual se van imprimiendo los cambios sociales acontecidos tras los golpes militares o el cambio en las relaciones de producción a partir del desarrollo de la economía petrolera, que generó una migración masiva del mundo rural hacia las ciudades creando contextos socioculturales favorables a la aparición de ciertas formas de religiosidad. En estas condiciones, el proceso ontogénico del mediador suele relacionarse con vivencias místicas infantiles asociadas a la falta de horizontes económicos y pasa por una dolorosa iniciación ritual tras la que el cuerpo "madura" para poder ser usado por espíritus benefactores, adquiriéndose el habitus espiritista. Esta deriva cultural, capitalizada a menudo por entidades político-religiosas ${ }^{8}$, tiene una clara réplica en los cambios sociales ocurridos en España durante los años cincuenta a setenta del siglo XX como resultado de la transformación del proceso productivo en el segundo período del franquismo, como se verá más adelante.

Los sanadores marialionceros presentan, según Ferrándiz (2004: 90-119), algunas características que conviene destacar: el aprendizaje en el entorno familiar, el doble

\footnotetext{
${ }^{6}$ Según Campos, los espiritistas caen en trances en los que, a diferencia de lo que acontece con los chamanes, se pierde la voluntad y la conciencia.

${ }^{7}$ Las enfermedades culturales o Culture-Bound-syndromes constituyen un conjunto de dolencias generalmente rechazadas por la medicina científica como disease. En nuestra zona de estudio son, sobre todo, el asiento y el mal de ojo. No obstante su tradicional vinculación con elementos culturales alejados de la biomedicina, existen hoy día analistas que las visibilizan en la praxis médica más ortodoxa, como sucede en el caso de la obesidad y la obsesión por la delgadez que señala Cheryl Ritenbaugh (1982: 347-364).

${ }^{8}$ Véase, por ejemplo, el fenómeno de la masiva conversión al protestantismo en Latinoamérica analizada por David Stoll (2002a, 2002b).
} 
origen curanderil y espiritista de las materias $^{9}$, el nomadismo, la dedicación generalizada a tiempo parcial, la práctica en barrios urbanos, el cobro por la curación y el corporativismo de los sanadores.

Algo muy distinto acontece entre los especialistas rituales aymarás del altiplano boliviano:

Los que nacen simultáneamente de un mismo vientre, los gemelos o ispa, así como aquellos que nacen de pie, kalluni, con más dedos de los que por naturaleza corresponden, sojtillos, y los que poseen ciertas marcas, defectos y deformaciones... (Fernández Juárez 2004: 20).

Estos sanadores o yatiris rurales difieren en gran medida de sus colegas urbanos, pues tienen la obligación moral de atender a sus clientes, con los que se obligan a comportarse del modo más honesto y transparente posible, mientras que los urbanos buscan enriquecerse y son poco cuidadosos en su procedimiento, que ejecutan de modo rápido, sin informar al cliente y sin intimidad (Fernández Juárez 2004: 38). En este sentido, los yatiris urbanos actúan de modo similar a los profesionales de servicios hospitalarios, cuya forma de asistencia despierta recelos en los usuarios porque actúan a la vista de todo el mundo y reflejan la situación del enfermo en historias clínicas (Fernández Juárez 2008: 37).

\section{LOS CURANDEROS DE NUESTRO ÁMBITO DE TRABAJO}

Hasta los años 50 del siglo XX, la mayor parte de itinerarios terapéuticos en nuestra localidad de estudio incluían exclusivamente los recursos domésticos y los curanderiles, mientras que el sector médico-profesional era poco frecuentado debido a su escaso prestigio y su elevado costo económico (De las Heras 2013: 674-675). En el ámbito de los sanadores folk han existido dos sectores muy distintos. Por una parte, los sanadores locales, sancionados y obligados en su práctica por la comunidad y, por otra, los externos al grupo social, tanto geográfica como culturalmente. Para una mayor claridad en la exposición los denominamos endo y exocuranderos, enfatizando de este modo su relación cultural con la comunidad a la que asisten. Podemos identificar en bastante medida a los integrantes del segundo grupo con las diferentes categorías del llamado curanderismo urbano.

Las características principales de los endocuranderos son las siguientes:

- No han elegido el oficio de curar, sino que éste procede de una obligación histórica y tácita para con el grupo social, de manera que la denegación de la asistencia genera violencia en las relaciones sociales. Por tanto, podemos afirmar que llevan a cabo un rol estructural que trasciende los límites de la atención a la salud.

- Su asignación como sanadores procede de determinados estigmas relacionados con el nacimiento, el principal de los cuales es la gemelaridad ${ }^{10}$. Otra caracte-

\footnotetext{
${ }^{9}$ Mediadores mediúmnicos del culto marialioncero, en cuyo cuerpo se encarnan las entidades espirituales que producen la sanación.

${ }^{10}$ Existe la creencia, entre una parte de la comunidad, de que sólo uno de los gemelos posee gracia, aunque lo más común es que se atribuya a los dos. De hecho, en el actual elenco de endocuranderos, existen dos hermanos gemelos de 72 años.
} 
rística que invoca el señalamiento para curar es la prematuridad, con una relación directa entre ambas variables, de modo que una persona sietemesina tiene más gracia $^{11}$ que otra nacida tras ocho meses de gestación y, ésta, a su vez, más que la que nace de un parto a término. Nacer el día de la festividad de Corpus Christi también confiere gracia. Especial significación tiene el hecho de haber llorado en el vientre materno, circunstancia que debe ser mantenida en secreto hasta el momento del nacimiento ${ }^{12}$. Una de nuestras informantes relata que su suegra oyó hacia 1940 "como un maullido" procedente del interior de su vientre grávido y, debido a la ansiedad que este hecho le produjo, lo desveló inmediatamente entre su red social. Tal conducta provocó el enfado de su marido ya que esa indiscreción anulaba la futura gracia del hijo, extremo que la madre ignoraba ${ }^{13}$. Obviamente, la coincidencia de varios de estos factores es determinante para cuantificar el poder resolutivo del endocurandero. Excepcionalmente, como acontece en una sanadora de mal de ojo, la gracia es heredable en función de la exigencia y el consentimiento de la comunidad.

- Los endocuranderos no pueden pedir dinero por su trabajo, se deben a la comunidad según se verbaliza en la expresión "lo han recibido por nada y por nada lo tienen que dar", sin perjuicio de que algunos pacientes, en agradecimiento, les hagan obsequios, pues este rasgo de curar por el amor de Dios no excluye, como han señalado otros autores (Martí 1989: 181), el principio de reciprocidad $^{14}$.

- Como expresión de su obligación con la comunidad y la naturalización que esto implica, los endosanadores carecen de un espacio específico para realizar su tarea. La mayoría de las veces curan en su domicilio y lo hacen en una habitación sin decorados, iconos ni significante alguno en relación con el acto de sanación. Otras veces se desplazan al domicilio de aquellos que solicitan sus recursos e, incluso, al hospital cuando están ingresados y existe la sospecha de

\footnotetext{
${ }^{11}$ La gracia es un concepto polisémico. En una de sus principales acepciones, la que vamos a seguir a continuación, tiene el significado de una atribución divina que es proyectada al individuo humano como un don que, para Pitt Rivers (1993: 291), discurre por dos circuitos distintos, uno de tipo contractual y otro basado en la generosidad. En términos religiosos, el primero se produce, como se ilustrará más adelante, en un contexto de reciprocidad entre la persona que realiza un ofrecimiento a cambio de un favor y la entidad espiritual que lo concede. En el segundo caso se trata de un don con el que Dios señala a una persona. En este sentido, los sanadores populares son considerados por la población como portadores de gracia.

${ }^{12}$ El hecho de haber llorado en el vientre materno es considerado un signo de gracia, que faculta para la sanación de diversas dolencias, en una amplia zona del sureste español, como señalan Grau García (2008: 41) en Murcia, Salazar Agulló et al. (1997: 51) en Elche, Rodríguez Molina (2002: 10) en Jaén y Gómez García (1996: 11) en Andalucía. Esta creencia se ha descrito también en algunos países de Iberoamérica, como República Dominicana (Sánchez Carretero 2007: 251-252) y Perú (Chávez Hualpa 2004: 79), en donde se constata su existencia desde el siglo XVI.

13 Cabe resaltar, a tenor de este hecho, que los padres debían experimentar satisfacción al saber que el hijo o hija poseía gracia. En nuestra etnografía se constata el empoderamiento del individuo señalado con la gracia —así como de su familia- que, por este signo se convierte en mediador social y, como consecuencia, en agente estabilizador de los paradigmas comunitarios.

${ }^{14}$ Estos obsequios son de poco valor, como un frasco de colonia u otro objeto personal. Lo más habitual es que no exista regalo alguno y, en palabras de uno de ellos — RMM, varón nacido en 1935-, que el sujeto atendido no dé "ni las gracias".
} 
que puedan padecer mal de ojo. En el pasado también podían incluirse como espacios de sanación los establos, pues también los animales de labor - ya desaparecidos de nuestro entorno- se consideraban susceptibles de padecer enfermedades como mal de ojo o asiento $^{15}$.

- El sanador no exige al usuario que tenga fe. Parece obvio que la persona que acude al curandero lo hace porque espera una solución a su problema, es decir que "cree" o, como suele verbalizarse — debido a la vergüenza generada por la crítica que la medicina hegemónica hace de los sistemas de salud no científicos-, "ni creo ni dejo de creer". Sin embargo hay pacientes que no creen en la gracia del curandero ni, por tanto, en la eficacia de su ritual curativo y son llevados a regañadientes. En tal caso se comparte la convicción de que tienen la misma probabilidad de ser sanados que las personas que sí tienen fe en el curandero y su gracia.

- Seguramente por su naturalización dentro del grupo social, a los sanadores folk locales no se les da el nombre de curanderos, sino que se relacionan con su actividad curadora. Por ejemplo, se identifican a través del término magnar, que describe el modo en el que se realiza la curación del asiento. Así, se verbaliza que cierta persona magna, que cuenta las verrugas, que quita el mal de ojo o que cura la quebracía, sin emplear el término curandero, que se reserva para los exocuranderos.

Al segundo grupo, que hemos denominado exocuranderos, pertenecen una amplia diversidad de sanadores que, a lo largo de la historia, se han desplazado a Casas de Juan Núñez para atender a su población, o lo han hecho en sus lugares de residencia, normalmente en las provincias de Albacete, Valencia y Alicante. Entre todos ellos, los más significativos han sido Graciano, curandero de Alatoz -población situada a dieciocho kilómetros de Casas de Juan Núñez-, que ejerció hasta finales de los años setenta y, en fechas más recientes, Paco y Lola, conocidos como "los curanderos de Petrel" (Alicante), que lo hicieron durante las dos últimas décadas del siglo XX. Graciano aplicaba estrategias de herbolaria y adivinación, mientras que los segundos — fundadores de la secta conocida como "el círculo de Paco y Lola" inspiraban para las curaciones en una filosofía de tipo kardecista.

En líneas generales, el grupo de los exocuranderos se caracteriza por una serie de propiedades antagónicas a las que se acaban de enumerar:

- Su poder procede de una autoinvestidura personal. Este fenómeno, producto de una experiencia mística o del reconocimiento por otro exocurandero de la gracia para curar, hace que las relaciones del sanador con las personas de la comunidad a la que atiende no tengan el carácter estructural que se aprecia en el caso anterior. Por dicho motivo estos sanadores son en ocasiones itinerantes,

\footnotetext{
${ }^{15} \mathrm{El}$ asiento —o empacho en países latinoamericanos- es una enfermedad producida por la retención de los alimentos en el intestino, a cuyas paredes se adhieren. Por esta razón también se le denomina "pega" en algunos entornos, como en Costa Rica. Puede generar sintomatología muy diversa como llanto (en los niños), fiebre, decaimiento y tristeza. Esta sintomatología también acontece en el caso de los animales de labor, que se vuelven improductivos. Tras la terapia, consistente en un masaje realizado con las manos - o con los pies en el caso de las caballerías - el cuadro clínico se resuelve mediante la evacuación de abundante diarrea.

16 Véase Reviriego (1992: 95-103).
} 
buscando una neocomunidad entre las personas de su ámbito de influencia, que puede alcanzar distancias mayores de los cien kilómetros. En el caso de los "curanderos de Petrel" existía una ubicación permanente en dicha población alicantina, así como en una finca de la cercana localidad de Biar y, además, un área que abarcaba parte de las provincias de Alicante y de Albacete, en la que se hacían visitas periódicas con sesiones de catequesis y apostolado.

- Los exocuranderos piden ser retribuidos e, incluso, son exigentes en este punto. Como la correspondencia material se produce siempre a partir de la evidencia de la curación - hecho que no ocurre con los médicos científicos privados, que siempre son remunerados curen o no- el curandero de Alatoz solía cobrar a través de terceras personas. Téngase en cuenta que, aunque esa población dista menos de veinte kilómetros de Casas de Juan Núñez, en los años sesenta e incluso setenta, no era fácil para muchas personas desplazarse de un lugar a otro y, por esta razón, le encargaban el pago a un convecino que tuviese que ir al curandero. Según nuestros informantes Graciano, debido a su gracia, sabía en qué consistía dicho pago y, por tanto, reconocía si éste se producía en su totalidad o si, por el contrario, el intermediario se había quedado una parte del mismo ${ }^{17}$.

- El espacio físico en el que el exocurandero realiza su tarea no suele ser anodino sino, por el contrario, fuertemente significativo. Frecuentemente contiene figuras o representaciones espirituales o elementos alegóricos de su poder. Por lo general las sanaciones se llevan a cabo en su domicilio pero, en el caso de los curanderos de Petrel, tenían también lugar en los pueblos que recorrían. En este caso, se trataba de un acto ceremonial realizado en un gran espacio -normalmente en un almacén- que se anunciaba días antes entre los vecinos del pueblo. Los propietarios, simpatizantes de la secta, cedían gratuitamente el local, donde se disponían los asistentes y curanderos formando un gran círculo. Paco, el curandero, comenzaba la sesión con un discurso en el que recordaba a los presentes el carácter sagrado de la asamblea y el suyo propio, llegando a afirmar que representaba a Jesucristo, encarnado en él.

— La curación exige previamente que el individuo tenga fe en el sanador — varios informantes incrédulos recuerdan que Graciano les había advertido "¿a qué vienes si no crees en mí?»— y, en caso contrario, llega a rechazarse la intervención. Por tanto, el sanador no se siente en absoluto obligado por los demandantes, sino que ejerce su gracia de modo privado, como ocurre en la medicina liberal. La fe en el curandero y en su arte deriva de su carisma, que está en la base de su prestigio.

\footnotetext{
${ }^{17}$ En relación con estos pagos, podemos afirmar que los exocuranderos de referencia para Casas de Juan Núñez — Graciano y el Círculo de Paco y Lola - se mantenían económicamente a expensas de las sanaciones realizadas, a diferencia de los endosanadores, para quienes la práctica curanderil no supone ingresos, debiendo sobrevivir de su trabajo en otros ámbitos, como la agricultura o los servicios. Así en los exocuranderos se produce una cierta profesionalización, como hemos visto que ocurría entre los neocuranderos urbanos, con los que entendemos que guardan una importante analogía. A la profesionalización por el aspecto de suficiencia económica se deben sumar otros factores, que a continuación se detallan, como la especificidad del escenario o la investidura personal.
} 
A continuación se muestran (tabla 1) los curanderos de referencia para Casas de Juan Núñez de los que tenemos constancia a lo largo del último siglo.

\begin{tabular}{|c|c|c|c|c|}
\hline Referencia personal & Tipo & Nacto./Defunc. & Actuaciones & Fuente de gracia \\
\hline Águeda García García & En & $1864 / 5-3-1944$ & Verrugas & Gemelaridad \\
\hline Catalina García Heras & En & $1867 / 1943$ & Asiento & Gemelaridad \\
\hline $\begin{array}{l}\text { Ángela Navalón Sánchez "la de } \\
\text { Lorito" }\end{array}$ & En & $1863 />1945$ & Quebracía, Partera & Desconocida \\
\hline Pedro Monteagudo García "el pavo" & En & $1875 / 17-9-1952$ & Asiento & Gemelaridad \\
\hline $\begin{array}{l}\text { Martina Gómez Belmonte "la del } \\
\text { Quemao" }\end{array}$ & En & $14-6-1882 / 24-10-1970$ & Verrugas, Esfarataos & Desconocida \\
\hline José Salas González "el Mocito" & En & $1891-1975$ & Verrugas & Desconocida \\
\hline Catalina González Parra & En & $12-1-1899 / 20-11-1986$ & Verrugas & Desconocida \\
\hline $\begin{array}{l}\text { Juan Antonio Legidos Abiétar, } \\
\text { "Cacherre el viejo" }\end{array}$ & En & $28-6-1899 / 8-2-1994$ & Asiento & Desconocida \\
\hline $\begin{array}{l}\text { María Honrubia Pérez "María de } \\
\text { Requeté" }\end{array}$ & En & $28-8-1900 / 9-3-1986$ & Verrugas & Desconocida \\
\hline $\begin{array}{l}\text { Juana Andújar Jiménez "la del } \\
\text { malcriao" }\end{array}$ & En & $2-5-1901 / 5-5-1984$ & Mal de ojo & Desconocida \\
\hline Teresa López Gómez & En & $18-1-1904 / 20-7-1992$ & Verrugas & $\begin{array}{l}\text { Haber llorado en el } \\
\text { vientre materno }\end{array}$ \\
\hline Dolores Moyano del Rey & En & $3-2-1926 / 4-1-1984$ & $\begin{array}{l}\text { Asiento, ¿Mal de } \\
\text { ojo? }\end{array}$ & Gemelaridad \\
\hline $\begin{array}{l}\text { Isabel Gómez Legidos, "la de } \\
\text { Paulinillo" }\end{array}$ & En & $28-1-1883 / 4-6-1948$ & Asiento & Desconocida \\
\hline $\begin{array}{l}\text { Ramón Moreno Moyano, "el de } \\
\text { Teodosio" }\end{array}$ & En & Nacido el 20-06-1935 & Asiento, Verrugas & $\begin{array}{l}\text { Gemelaridad, } \\
\text { prematuridad, nacer } \\
\text { en Corpus }\end{array}$ \\
\hline $\begin{array}{l}\text { Adoración Davia Mañas, "la del } \\
\text { melgo" }\end{array}$ & En & Nacida el 8-10-1941 & Asiento, Verrugas & Gemelaridad \\
\hline Aniceto Davia Mañas, "el melgo" & En & Nacido el 8-10-1941 & Asiento, Verrugas & Gemelaridad \\
\hline Pedro Antonio Valero “el molinero" & En & $14-04-1910 / 2010$ & Verrugas & Prematuridad \\
\hline Emilia Martínez García & En & Nacida en 1939 & Verrugas & Desconocida \\
\hline Remedios Jiménez Tolosa & En & Nacida el 18-9-1964 & Verrugas & Desconocida \\
\hline Benilde Jiménez López & En & Nacida el 10-06-1967 & Mal de ojo & Herencia \\
\hline Graciano "el curandero de Alatoz" & Ex & $1937-1977$ (1) & $\begin{array}{l}\text { Toda enfermedad } \\
\text { (2) }\end{array}$ & Autoinvestidura \\
\hline $\begin{array}{l}\text { Paco y Lola "los curanderos de } \\
\text { Petrel" }\end{array}$ & $\mathrm{Ex}$ & $1982-1989$ (1) & $\begin{array}{l}\text { Toda enfermedad } \\
\text { salvo el cáncer }\end{array}$ & Designación divina \\
\hline
\end{tabular}

TABla 1.-Curanderos de referencia en Casas de Juan Núñez. En: endocurandero/a; Ex: exocurandero/a. (1) Período en el que ejercicio la sanación. En el caso de los curanderos de Petrel, en 1989 falleció Lola, y Paco siguió realizando sanaciones en su sede alicantina, donde continuó atendiendo a algunas personas de Casas de Juan Núñez. (2) Los motivos de consulta recogidos en nuestro trabajo de campo hacen referencia a: no comer/desgana, dolores de cabe$z a$, pupas por todo el cuerpo, dolor de estómago, asiento, urea en la sangre, afonía, falta de regla, vómitos, flojedad, tos, maltas, esterilidad y dolor de buesos. 
Los procesos asistidos por los endocuranderos en la actualidad en Casas de Juan Núñez son el asiento, el mal de ojo y las verrugas, pero anteriormente existieron también arregladores de huesos, que atendían a los "esfarataos" o luxados, y de hernias o "quebracías". La especificidad de la gracia para curar no obsta para que estos sanadores sean requeridos en otras patologías como el cáncer o enfermedades que cursan con dolores intensos — aún a sabiendas de que no poseen capacidad para curarlas - ya que el contacto de sus manos suele producir alivio en el cuerpo enfermo. En cuanto al segundo grupo nunca ha habido exocuranderos instalados en Casas de Juan Núñez y ese tipo de servicios ha sido históricamente prestado por sanadores de otras poblaciones ${ }^{18}$, abordando en general todo tipo de dolencias. No tenemos constancia de que hayan existido históricamente problemas de competencia entre ambos tipos de curanderos aunque sí, en el caso del exocurandero Graciano —que se verá más adelante- existió una cierta relación de empoderamiento frente a los endocuranderos. Así, este sanador no magnaba a sus pacientes y, cuando lo consideraba necesario, ordenaba a sus pacientes que se hiciesen magnar por los endosanadores locales, reproduciendo en cierto modo las relaciones de poder que existían en ese período histórico entre médicos y enfermeros.

Queremos significar la notable homología que se puede constatar entre exocuranderos y yatiris urbanos, que exigen un pago y adoptan investiduras próximas a los médicos profesionales. El interés económico está menos presente entre las materias marialionceras que, no obstante, adoptan estrategias similares a las de los exocuranderos de Petrel que se describen más adelante. Otro elemento común al marialioncismo y al círculo de Paco y Lola de Petrel es su nacimiento institucional como respuesta a una crisis político-social tratando de recuperar determinados valores morales. La categoría de endocurandero muestra rasgos comunes con los yatiris rurales del altiplano boliviano, como el estigma de la gemelaridad o la solidaridad desinteresada. No pretendemos con estas observaciones universalizar los tipos de curanderos ni los contenidos de sus actuaciones sino únicamente constatar la reiteración de ciertos rasgos, circunstancia que probablemente debería ser estudiada con más profundidad en otro trabajo de investigación.

\section{LA CONSTRUCCIÓN SOCIAL DEL ENDOCURANDERO EN CASAS DE JUAN NÚÑEZ}

Históricamente nuestra comunidad de estudio ha accedido a los servicios curanderiles para hacer frente a sus problemas de salud (De las Heras 2013: 511-579) y, hasta los años setenta del siglo XX, estas consultas superaban en número a las realizadas a los médicos profesionales, sector que gozó de escaso prestigio hasta los años cincuenta y que resultaba excesivamente caro para los usuarios, como ya se ha referido. Dado el escaso espectro asistencial de los endosanadores, apenas limitado al mal de ojo, la quebracía, el asiento y las verrugas, la mayor parte de asistencias eran realizadas por el curandero de Alatoz —exosanador-, al que se reconocía capacidad para tratar cualquier tipo de enfermedad. Los curanderos ubicados en la localidad han

\footnotetext{
${ }^{18}$ Sobre todo Albacete, Almansa, Casas Ibáñez, Villar de Chinchilla y diversos puntos de la Comunidad Valenciana.
} 
sido hasta la actualidad exclusivamente endosanadores. Aunque, como ya se ha dicho, los estigmas ligados al nacimiento bastan para acreditar - y exigir - el don, hemos hallado testimonios que aportan mayor información acerca de la construcción social del endocuranderismo. Se trata de tres mujeres de la misma familia que no han llegado a ejercer la sanación, pero cuyo don ha sido parcialmente reconocido por otras personas de su entorno. Las llamaremos M1, M2 y M3 ${ }^{19}$.

La primera de ellas fue M1, nacida en 1931 y fallecida en 1965. Era la séptima de ocho hermanos, de los que solo dos eran hombres, y su madre no había tenido ningún hermano varón pues era la cuarta de diez hermanas ${ }^{20}$. M1 poseía un carácter peculiar:

...tenía muy mal genio, tenía...no sé, así como una malcriá era... más malcriaíca creo yo que era... o era que era como tú a la otra, que era más... tenía un poco de envidia...

\section{A los catorce años enfermó}

...cuando tenía 14 años, dicen... que tú esto no lo vas a creer, pero algo hay, ... de que se lavaban la cabeza con la regla o eso, y dicen que se les retiraba, o les venía mal, o se ponían algún... les venía como alguna enfermedad. Y entonces, cuando aquello, cuentan de que ella se lavó la cabeza aunque... y se puso mala. Se puso mala y le dio mucha fiebre, le daba mucha fiebre, le daba... no sé... eran como si fuese ataques, pero ataques no le daban, porque después de mayor, ataques, yo he visto a P., por ejemplo, cuando le dio el ataque aquel, si fue epilético o lo que fuera, y a mi padre le he visto dar ataques epiléticos, y a mi tía ataques de esos no le daban...eran como rabietas, como... cosas así o nerviosas o depresivas o algo quizá fuera, pero aquello era más bien fiebre, con mucha fiebre...

Los padres iniciaron un itinerario de médico en médico, empezando por los dos que ejercían en el pueblo y siguiendo por otros privados de la capital, pero ninguno sabía cuál era la causa de esos síntomas. La enfermedad fue empeorando y, tras diecinueve años de evolución, condujo a M1 a la muerte:

...se le hacían unos agujeros... unos agujeros, a lo mejor tenía un agujero aquí, que le supuraba...

¿En el muslo?

En el muslo, en la rodilla, en la cadera, en la ingle...

¿Como granos o...?

Era como un grano, pero se le hacía agujero. Y le supuraba puz, porque eso yo me acostaba allí con ella y la veía,... mi tía R. la curaba. Y yo la veía lo que ese, le echaba...

\footnotetext{
${ }^{19}$ Mediante el uso de iniciales se pretende mantener el anonimato de estas tres mujeres, dado que ninguna de ellas llegó a ejercer como curandera por deseo propio y si se muestran aquí es exclusivamente para ilustrar las características y estigmas que gravitan en la construcción social del endocuranderismo, aparte de los signos ya referidos, vinculados al nacimiento. En estos tres casos, la negativa a curar obedece a motivos personales y no a temor a la exclusión o rechazo. Por el contrario, el rol de endosanador, tanto en hombres como en mujeres, genera habitualmente respeto por parte de la comunidad y es un atributo de prestigio social. Todos los testimonios reflejados acerca de estas mujeres proceden de la misma informante.

${ }^{20}$ Aparece aquí un signo que en el folklore español se ha vinculado tradicionalmente con la gracia: ser el séptimo hijo. En este caso se une a una peculiar desviación de la distribución normal de géneros en la familia, con diez mujeres y ningún varón en la fratría de la madre y seis mujeres y sólo dos hombres en la de M1.
} 
metía gasas, gasas, y después se las sacaba, todo y ese... y cuando se murió, se murió de 33 años, ya ves. Estuvo desde los 14 hasta los 33 años, estuvo a base de eso...

A lo largo de ese tiempo, M1 dejó de andar y, con dificultad, se desplazaba valiéndose de una silla. La familia trató de buscar en la gracia una explicación a la enfermedad

...es que decían que ella tenía gracia, gracia de curar, o... esa gracia o ese mal que tenía era de no haber curao... porque tú sabes que los curanderos, o hay gentes, que si curan no les pasa a ellos nada...

La informante ignora la causa de la gracia, ya que en M1 no se había dado ninguno de los principales estigmas sancionados colectivamente para conferirla. Sencillamente, era la única explicación para este caso, en el que los profesionales no habían hallado causa alguna, asociada a la idea de que la gracia no empleada en los demás se vuelve contra el que la posee. En el certificado de defunción de M1 figura la rúbrica diagnóstica "caquexia", término médico que indica una consunción grave del organismo pero no desvela la causa de la misma - la cual permanecía por tanto desconocida a los diecinueve años de haber comenzado - sino, tan solo, un estado terminal al que abocan distintas enfermedades y que da a entender que la muerte está próxima. Si la gracia proviene de Dios y la enfermedad procede de no haberla aplicado, ¿por qué Dios no había advertido a M1 de su don? Tal vez se trata de un camino personal en el que acontece la catarsis y en ella no se llegó a dar a causa de su mal carácter, según sus familiares. El hecho es que, a los ojos de éstos, el mal ya no tenía remedio, es decir que una vez que empezó a padecer esas fiebres y supuraciones, ya no le habría valido curar para recuperar la salud. La adscripción de gracia para curar se fundamenta así en un mandato divino y se representa con un atrezo característico de la tradición católica. Para la informante el elemento más importante radica en el incumplimiento de la obligación de curar, por cuya razón recibe el castigo de una enfermedad que, por otra parte, reviste características próximas a las de algunas figuras de la Historia Sagrada cristiana.

La segunda mujer, M2, reside actualmente en otra población y posee cierta capacidad para adivinar sucesos que acontecen en otros lugares a distintas personas, por ejemplo a miembros de su familia:

...me está pasando algo y le llamo y le digo "A..." "sí, no hace falta que me digas" [respuesta de A]

¿Y lo sabe?

Sabe qué me está pasando

El origen del don, en este caso, se relaciona con un milagro obrado por la Virgen de Cubas

...esa estuvo muerta... y... muerta cuando era pequeña, y le pidieron a la Virgen de Cubas, y la... y se curó... y esa también decimos que tiene gracia. Yo particularmente, y alguien de mi familia, lo vemos... y no tiene...

¿La gracia le vendría a partir de la curación esta...?

De la curación. Pensamos que puede ser que tenga esa gracia por... por la fe de la Virgen... 
Aunque, más adelante, aparece otra posible causa de la gracia

...su madre que está muerta, que la está ayudando...

M2 es sabedora de su poder adivinatorio, que se relaciona en nuestra comunidad con la posesión de gracia y, sin embargo, rechaza poseer un don para curar o para ayudar a los demás. Esta conducta es generadora de violencia, su familia la considera desafortunada y la informante recrimina a M2 su negativa a realizar curaciones, augurándole un final similar al acontecido en el caso anterior. Por otra parte ha observado, que esta persona, cuando intenta tranquilizar a otros vecinos o darles buenos consejos, se pone enferma:

...otro de mi familia está malo... mi madre mismo, si ahora viene y la ve "venga tía, esto, lo otro" y eso, y luego ella llega a su casa y mi madre se ha puesto a lo mejor un poco mejor, y llega a su casa y ella se pone mala... pero mala, también. Y es que ella, se transmite el mal que tiene para poderla curar... entiendes... y eso son las personas que decimos que tienen gracia... Ahora, hay personas que lo transmiten, que ayudan a otras personas que están malas, y entonces ella el mal suyo lo pasa, pero la persona que está lo cura... la cura, la pone mejor...

La familia, en definitiva, no consigue que esta presunta sanadora, a pesar de tener una fuente plausible de gracia - la curación milagrosa en su infancia por la Virgen- y de exteriorizar ésta de modo indudable en forma de capacidad para adivinar, practique curaciones. A esto se suma el riesgo potencial de sufrir un "castigo" como su tía, que por una razón más leve - ya que ignoraba su poder- fue condenada a una penosa enfermedad, que conllevó el aislamiento social y la muerte precoz. La causa de la negativa es la no asunción del don, postura posiblemente ligada al cambio de paradigma cultural sufrido por M2 que, tempranamente, se trasladó a vivir a la ciudad y se socializó parcialmente en una cosmogonía urbana.

Existe entre este caso y el anterior una notable diferencia en el devenir del mal. Mientras en el primero la persona es estigmatizada con él por no haber usado su gracia, en el segundo lo es justamente cuando se da el caso contrario. Tras esta contradicción parece latir la obligación de curar y la necesidad de tener fe. Posiblemente si M2, según nuestra informante, hubiese reconocido su señalamiento divino y hubiese obrado en consecuencia — esto es, dedicándose a curar a otros- habría logrado disipar el mal contagiado cuando eventualmente ayuda a alguien y que, por su falta de fe, permanece en su interior sin hallar la salida hacia el mundo espiritual. La transferencia del mal es un fenómeno ampliamente descrito en el curanderismo - tanto desde el enfermo a determinados objetos como a otras personas ${ }^{21}$, entre las que se incluye el propio sanador-y también acontece en los citados "curanderos de Petrel" Paco y Lola. Antes de tomar conciencia de su capacidad para curar, Paco contraía las dolencias de los enfermos a los que se acercaba, según sus propias palabras (Reviriego 1992:97).

El tercer y último caso está representado por la madre de M2 -ya fallecida-, cuya gestación habría sido favorecida por la Virgen de Fátima, circunstancia considerada como su fuente de gracia:

${ }^{21}$ En nuestra etnografía se observa a menudo la transferencia de verrugas a objetos enterrados, así como a terceras personas, proceso que también acontece en el caso de los orzuelos. 
...estaban en una aldea, en la sierra, y estaban casi dos años sin tener familia. Y como, en aquellos tiempos, como ... se casaban para tener hijos y para... pues, como no tenían, pues ella pensaba que podía ser ya la falta en ella o en él... y le dijieron, vino aquí a la fies... un día al pueblo con... a ver la madre y tal, y entonces dijeron "van a traer a la Virgen de Fátima", que fue cuando se apareció, mas o menos, y la trajeron aquí a España, a hacer un recorrido por España, por la... por los pueblos de España la traían isabes? Y le dijeron que la iban a pasar por aquí, por las Casas [...] y entonces, ellas le dijeron "tal día va a venir", y ella, con el conqué, le dijo a mi padre que viniera con ella a pedirle a la Virgen para que tuvieran... si era por uno o por el otro... pa que tuvieran. Y le dijo que sí, pero a la hora de venir, por lo visto... que si le salió faena o algo,... entonces mi padre no vino... le dijo "veste tú, que yo no me puedo ir, veste tú y pídele por ti y por mín o algo así. Y entonces vino, y se vino con un tío mío y, al llegar aquí, entró por las portás, a casa de mi abuela, pensando que la Virgen iba a... eran las cinco o las seis de la tarde cuando... y entonces dijeron "ahora vienes, que ya se ha ido la virgen, te estábamos esperando, pensábamos que ibas a venir y..." "¡cómo! ¿Qué ha venío la Virgen?" y la pobre desesperá y, pos se quedó... amargá, porque ella venía a ver a la Virgen y a pedirle que... que... de tener hijos. Y entonces, la pobre hija, la pobre, se fue al corral que, entonces, como no había váter ni ná, pues se fue al corral... a llorar y a desahogarse... Y entonces, dice que le pidió a la Virgen que quería... que si fuera por uno o por otro, que pedía de tener hijos. Y a los nueve meses... a los nueve meses de... y a la misma hora, dice que nació mi hija... mi hermana. Y sin dolores y sin nada. Y fue cuando te contó todo el parto...

¿Entonces ella lo interpretó como un milagro que había hecho la Virgen?

Claro, claro...

En esta mujer el don se manifestaba igualmente en forma de capacidad adivinatoria, aunque de un modo menos intenso y, tal vez por ese motivo, no había despertado en la informante y su familia la necesidad de convencerla para que curase. También puede influir el hecho de que la vivencia en la que, con mayor dramatismo M2 habría sido iluminada por el don, hubiese tenido que ver con el honor de la familia. Esta mujer alteró en cierta ocasión el recorrido fuera de casa que realizaba sin variación todos los días desde hacía años, guiada por una voz interior y, de este modo, sorprendió a su marido mientras la engañaba con otra mujer. Ello motivó la exclusión del marido, desacreditado ante su familia extensa, que cerró filas en torno a ella. La función creadora de la virgen de Fátima, autora final de la gestación que dio la existencia a M2, se convierte posteriormente en ejecutora del castigo por trascender las normas sociales.

A la solidaridad obligada se añade el acatamiento a las normas, dos elementos esenciales en el mantenimiento del orden social, conjurado por la permanente vigilancia del mundo espiritual — la Virgen de Cubas, la de Fátima, el alma de los antepasados difuntos- a través de los ojos de las personas señaladas.

\section{EXOCURANDEROS DE CASAS DE JUAN NÚÑEZ: GRACIANO Y EL “CÍRCULO DE PACO Y LOLA"}

El principal exosanador de nuestra comunidad fue Graciano, que residía en una aldea de Alatoz y utilizaba una gestualidad y un decorado especialmente dramáticos para atender a los enfermos, cuya curación residía necesariamente en una fe ciega. Su ejercicio está confirmado entre 1944 y 1977, aunque disminuyó notablemente a 
partir de la instauración de la Seguridad Social. En contadas ocasiones emitía diagnósticos, que se referían a cuatro entidades - flojedad, haber cogido frío, tener algo malo o padecer asiento- y sus tratamientos se basaban en remedios vegetales, a veces en ciertos alimentos y, con frecuencia, en su poder mágico. La eficacia de dichos recursos junto a su bajo precio, en contraposición a la elevada carestía de los medicamentos de patente, eran elementos cruciales que fidelizaban su clientela.

En este mismo grupo Paco y Lola ocuparon el nicho vacante de Graciano. Residían en Petrel, en donde dirigían un colectivo con atributos de communitas $^{22}$, exigían fe y dinero, utilizaban una performance singular y relacionaban su poder con el designio divino. Su filosofía propugnaba el carácter moral de toda enfermedad y se materializaba en una práctica híbrida entre el kardecismo y el fundamentalismo cristiano. Contaron con un moderado seguimiento en Casas de Juan Núñez hasta los años noventa del siglo XX. El fallecimiento de Lola en 1989 produjo una importante caída de esta institución, cuyas actividades se ciñeron el ámbito de su área de mayor influencia - Petrel y Biar - aunque el espíritu de Lola seguía presente en las ceremonias de sanación ayudando a su marido desde el más allá (Longarela 2000: 65).

El remedio para todas las enfermedades se basaba en el uso de agua bendecida por Paco, tanto bebida como aplicada sobre el cuerpo o, sencillamente, colgada del cuello a modo de un amuleto protector. Los usuarios que no residían en el recinto de la comunidad la recogían en sus domicilios a las nueve de la noche ya que, a esa hora, Paco pronunciaba desde Petrel la oración o requilorio, que la bendecía. Además, debían observarse ciertas precauciones con respecto a los "seres oscuros" o almas de los difuntos, que constituían una pieza clave en la patogenia de las enfermedades y cuyos designios eran conocidos por Paco, debido a su poder mediúmnico. Se trataba, en general, de evitar la entrada al mundo de los vivos de ciertos espíritus - a menudo familiares - de naturaleza malvada para evitar el acogimiento, proceso por el que dichas almas poseían el cuerpo del vivo causándole diversos síntomas ${ }^{23}$.

Entendemos que la eficacia del ritual de Paco y Lola parte del habitus que incorpora la noción de "libertad de búsqueda para la curación", inserto en el medio rural por el carácter más holístico de su naturaleza en relación con el medio urbano (Samuelsen y Vibeke 2004: 5). Continuando con las propuestas de Bourdieu, el campo engloba todas las alternativas terapéuticas, incluyendo a los curanderos. Éstos detentarían un capital simbólico que los ubicaría en una situación de poder. Por esta razón la performance trasciende el antagonismo de clases —que está impreso en su argumento de ricos y pobres - para configurar una relación de poder particular entre los que predican la norma - los curanderos-y los creyentes conversos, consti-

${ }^{22}$ Estos atributos, estudiados por Turner en su etnografía sobre los ndembu, incluyen la uniformidad, la sumisión, la abstención sexual e, incluso estrategias de humillación que persiguen trazar un "borrón y cuenta nueva" que destruya el estatus previo de los neófitos y los reinscriba en los saberes colectivos del grupo (Turner 1969: 103). En la finca que Paco y Lola poseían en Biar sus seguidores vestían prendas blancas con el emblema de la comunidad, maridos y esposas dormían en zonas separadas y todos ellos trabajaban gratuitamente para los líderes, a quienes habían donado previamente sus bienes. Sólo podían salir del recinto o mantener relaciones sexuales cuando éstos lo autorizaban.

${ }^{23}$ Una descripción más extensa acerca de los seres oscuros y el acogimiento puede consultarse en Reviriego (1992: 119-125). 
tuidos en una communitas. Así, lo esencial del proceso no es la existencia de Paco y Lola, sino la disposición de los creyentes a acatar la norma ${ }^{24}$, lo que se produce, precisamente, por las coincidencias en este caso entre norma y habitus en cuanto se refiere al orden, la obediencia y la entrega - elementos necesarios para la reproducción del clan-, el respeto a la Naturaleza — vinculado a cuestiones de supervivencia- y la asexualidad, contra los valores impuestos por una cultura liberal hegemónica y exógena - al menos en el momento de la socialización primaria de los actores que nos incumben- que el catolicismo no ha sabido contestar. Lejos de ello, los ha incorporado de facto contra sus propios principios doctrinales. Dichos contra-valores serían, entre otros, la arbitrariedad, el individualismo, la sensualidad, la acumulación de bienes y la falta de sensibilidad hacia el medio natural.

Las distancias que hemos constatado entre endo y exocuranderos parecen análogas a las que se dan en otros entornos, como es el religioso. Así, la principal advocación local es la Virgen de Cubas, cuyo santuario se halla a pocos kilómetros de Casas de Juan Núñez, pero existen también otras devociones, que podríamos calificar de "Secundarias" en cuanto se refiere a la frecuencia de su uso y la filosofía que las impregna. De este modo, mientras la Virgen de Cubas es considerada una identidad vinculada a la comunidad, con la que se ve obligada a dar curso y solución a toda tribulación en base a un pago simbólico u "ofrecimiento" ${ }^{25}$, los demás numina conceden las peticiones con carácter potestativo. En esta configuración se produce un empowerment del espacio religioso ordinario, que posee elementos iconográficos de la religión oficial, del mismo modo que en el proceso de salud/enfermedad/atención la mayor parte de nociones y transacciones se producen en la esfera popular (Kleinman 1978: 86) subordinada que, por otra parte, toma un amplio repertorio de nociones, modelos y remedios del imaginario médico-científico.

\section{DE LA MANCHUELA ALBACETENSE A LOS ESCENARIOS AMERICANOS}

El curanderismo urbano reflejado en el análisis de Roberto Campos (1998) nace de la proletarización del campesino y su reubicación en la periferia de ciudades grandes, un fenómeno semejante al acontecido en la Europa posindustrial. En ambos casos el nuevo ciudadano, perdido en un caos de nuevos sistemas de valores y creencias, busca el apoyo de otros individuos en situación semejante a la suya y se acultura lentamente en el nuevo paradigma. En este proceso se da la incursión de elementos culturales ajenos - tanto a la ruralidad como a lo metropolitano- que contribuyen a configurar nuevos espacios de análisis e interpretación de la realidad. La anomia

\footnotetext{
${ }^{24}$ Véase al respecto la interpretación de Prat con respecto al modelo de conversión propuesto por Lofland y Stark (Prat i Carós 2007: 122-125).

${ }^{25}$ El ofrecimiento es una promesa realizada, habitualmente por mujeres, al numen a cambio del favor solicitado. Puede consistir en un regalo, como flores o ropa para vestir la imagen de la Virgen, pero con frecuencia implica un sacrificio corporal, como recorrer andando la distancia hasta el santuario o realizar algún tramo de rodillas. Un ofrecimiento común que se ha perpetuado hasta nuestros días consiste en cortarse el pelo tras la boda para llevárselo en forma de trenza a la Virgen, con la finalidad de pedirle felicidad en el matrimonio. Los ofrecimientos no cumplidos en vida son heredados por las hijas y otras mujeres de la familia.
} 
durkheimiana es conjurada mediante una reestructuración de elementos culturales que provee una neoidentidad a la que no puede ser ajeno el proceso de salud/enfermedad/atención. Así, mientras en las comunidades rurales los sanadores son sancionados colectivamente y se les aplica un mandato social, en el caso del curanderismo urbano es el individuo quien decide si va a ejercer o no el arte de sanar. Por otra parte, los sanadores rurales suelen actuar en un ámbito local, ya que cada comunidad cuenta con los suyos, fortaleciendo con su ejercicio los lazos sociales y culturales. Debe reseñarse que en nuestra zona, probablemente en toda España, la práctica curanderil urbana no se aplica especialmente a los colectivos más desfavorecidos, sino que entre su clientela no parece haber diferencias socioeconómicas (Reviriego 1992: 155) ${ }^{26}$. En esta circunstancia han influido diversos factores, tal vez los principales sean el modelo de Asistencia Sanitaria universal y la caída de la morbimortalidad que, asociada a la política intrusiva de la sanidad oficial en lo privado - es decir, la progresiva medicalización de la sociedad-, recalifica las estrategias curativas como objetos de consumo ${ }^{27}$, desnaturalizando el arte curanderil con respecto a su principal función, la de curar. Por otra parte, en el tipo de curandero descrito por Campos existe una transmisión hereditaria familiar, debe mediar - al contrario de lo que acontece con frecuencia en nuestro medio rural- voluntad y vocación, y no precisa ritual iniciático, ya que la praxis hace al curador. Aparte del aprendizaje familiar, este sanador nutre su arte mediante otros recursos, como libros y revistas médicos, de esoterismo, de herbolaria, cursos oficiales de higiene y nutrición o conocimientos transmitidos a través de amistades.

En dicho estudio y en el análisis de Ferrándiz (2004) sobre el culto marialioncero en Venezuela se reflejan rasgos semejantes en la construcción social del curandero, donde predomina el aprendizaje sobre lo congénito, la investidura en el ámbito familiar, el ejercicio en barrios periféricos o el pago por las curaciones. Es decir, la identificación con lo que hemos catalogado como exocuranderismo. En el trabajo de Ferrándiz llama particularmente la atención la noción de rebusque, "prácticas económicas informales que se orientan fundamentalmente a la supervivencia del día a día", que motivan peleas en torno a la ortodoxia de la práctica espiritista. Una situación análoga se puede verificar en la ciudad de Villena, importantísimo núcleo del exocuranderismo en el que una proporción mayor del $70 \%$ de su población afirma ejercitar la magia y la medicina popular ${ }^{28}$ (Contreras Gil 2002-2010). El interés de esta constatación radica en que el valle del Vinalopó — la región en la que se ubica dicha población- ha constituido históricamente un referente curanderil para Casas de Juan Núñez, sobre todo a través de los curanderos itinerantes de Petrel. En etapas más recientes, este protagonismo se ha desplazado a la población de Almansa (Albacete), probablemente heredera del curanderismo alicantino según se desprende de nuestra etnografía (De las Heras 2013: 564-576).

\footnotetext{
${ }^{26}$ Esta circunstancia, que se describe en otros lugares, alcanza un tinte especialmente llamativo en los hospitales indígenas bolivianos, donde la medicina tradicional kallawaya es paradójicamente utilizada por clases medias y turistas (Flores Martos 2004: 194-200).

${ }^{27}$ La conceptualización exotizante de estas prácticas parece actuar entre las clases medias como un elemento catártico para los sentimientos de culpa colectivos, es decir una puerta a su redención.

${ }^{28}$ Entendemos por el contexto del artículo que, con la referencia medicina popular, el autor quiere referirse al curanderismo y no a la medicina doméstica tradicional.
} 
Llama, por último, poderosamente la atención el paralelismo entre las jerarquías curanderiles aymará que describe Gerardo Fernández Juárez (2004; 2008) y las categorías que se constatan en nuestra población de estudio, así como las modificaciones que acompañan a estas prácticas a lo largo de su proceso de institucionalización, hecho éste que también pone de manifiesto Juan Antonio Flores (2004) entre los kallawayas bolivianos.

\section{A MODO DE CONCLUSIÓN}

Existen en nuestro medio y su área de influencia dos tipos de curanderos: endocuranderos, sancionados localmente por la comunidad, que cumplen un papel estructural en el grupo social, y exocuranderos, culturalmente fuera del paradigma local. Mientras que los primeros vienen obligados a utilizar su gracia y su servicio es gratuito —-son los "funcionarios" de la salud folk-, los segundos obedecen en mayor medida a las leyes de mercado, siendo elementos significativos el pago por acto y el prestigio personal.

Esta categorización del entorno curanderil se constata igualmente en otras comunidades, como revelan las etnografías realizadas en diversos países del centro y el sur de América.

En la construcción del exocurandero parecen intervenir en nuestro objeto de estudio la magia contagiosa y, sobre todo, la influencia de la ideología católica, tanto en lo que respecta a sus entidades espirituales como a la noción de sacrificio relacionado con el bien.

La diferencia entre exo y endocuranderos reproduce la que existe en otros ámbitos, como en el religioso entre devociones locales y externas, o en el médico-científico entre médico de cabecera y médicos privados.

\section{BIBLIOGRAFÍA CITADA}

Ackerknecht, E. H. 1985. Medicina y antropología social. Madrid: Akal.

Briones Gómez, R. 1999. "Creencias y salud: curanderos y prácticas sanatorias", en Rodríguez Becerra, S. (coord.), Religión y cultura, tomo I: 247-267. Sevilla: Consejería de Cultura de la Junta de Andalucía y Fundación Machado.

Campos Navarro, R. 1998. Nosotros los curanderos. México: Nueva Imagen.

Comelles, J. M. 1997. "De las supersticiones a la medicina popular. La transición de un concepto religioso a un concepto médico", en González Reboredo, X. (ed.), Medicina popular e antropoloxía da saúde. Actas do Simposio Internacional en bomenaxe rendida a D. Antonio Fraguas: 247280. Santiago de Compostela: Consello de Cultura Galega.

Contreras Gil, F. 2002-2010. "Villena, el valle de los curanderos". Disponible en http:// www.comentariosdelibros.com/articulo-villena-el-valle-de-los-curanderos-24a128u2s.htm (Consulta: 10/ 01/2014).

Chávez Hualpa, F. Y. 2004. "Conmigo vas a trabajar: sueño iniciático entre las parteras andinas de Piura, Perú". Dimensión Antropológica 11 (32): 69-87.

De las Heras Salord, J. 2013. Vivir, enfermar y morir en Casas de Juan Núñez (1871-2005). Tesis doctoral. Facultad de Medicina de Ciudad Real. Universidad de Castilla la Mancha.

Devesa Jordá, F.; Pellicer Bataller, J.; Ferrando Ginestar, J.; Borghol Hariri, A.; Bustamante Balén, M.; Ortuño Cortés, J.; Ferrando Marrades, I.; Lull Sala, J. A.; Sintes Marco, M.A.; Nolasco Bonmatí, 
A. y Fresquet Febrer, J. L. 2005. «Persistencia de una práctica de medicina mágico-religiosa para la cura del empacho entre los enfermos que acuden a consultas externas de digestivo". Gastroenterología y Hepatología 28 (5): 267-274.

Durkheim, E. 1995. La división del trabajo social. Madrid: Akal.

Erkoreka Barrena, A. 1989. "Patologías por las que se recurre a santuarios en el País Vasco", en Álvarez Santaló, C.; Buxó i Rey, M. J. y Rodríguez Becerra, S. (coords.), La religiosidad popular, tomo III: 338-352. Barcelona: Antrophos.

Erkoreka Barrena, A. 2005. "Mal de ojo: una creencia supersticiosa remota, compleja y aún viva". Munibe 57: 391-400.

Fernández Cuesta, E. 1996. "Usuarios de curanderos en el área hospitalaria norte de la provincia de Granada", en González Alcantud, J. A. y Rodríguez Becerra, S. (eds.), Creer y curar: la medicina popular. Granada: 337-360. Granada: Diputación Provincial.

Fernández Juárez, G. 2004. Yatiris y ch amakanis del altiplano aymara. Sueños, testimonios y prácticas ceremoniales. Quito: Abya-Yala.

Fernández Juárez, G. 2008 "Confesiones de mandil blanco", en Fernández Juárez, G., González González, I. y García Ortiz, P. (coords.), La diversidad ante el espejo: salud, interculturalidad y contexto migratorio: 29-50. Quito: Abya-Yala.

Ferrándiz Martín, F. 2004. Escenarios del cuerpo. Espiritismo y sociedad en Venezuela. Bilbao: Editorial de la Universidad de Deusto.

Flores Martos, J. A. 2004 “Una etnografía del 'año de provincias' y de 'cuando no hay doctor'. Perspectivas de salud intercultural en Bolivia desde la biomedicina convencional", en Fernández Juárez, G. (coord.), Salud e interculturalidad en América latina. Perspectivas antropológicas: 181-212. Quito: Abya-Yala.

Fresquet Febrer, J. L.; Devesa i Jordá, F.; Pellicer i Bataller, J. y Campos Navarro, R. 2006. L'enfilt: una malaltia de la medicina popular. Gandía (Valencia): CEIC Alfons el Vell, AISSA.

Gómez García, P. 1994a. "La interpretación del curanderismo". Demófilo 12: 111-116.

Gómez García, P. 1994b. "Oficio de curandería: creencias, prácticas, relaciones, paradigmas”. Demófilo 13: 35-65.

Gómez García, P. 1996. "Teorías étnicas y etnológicas sobre la terapéutica popular", en González Alcantud, J. A. y Rodríguez Becerra, S. (coords.), Creer y curar. La medicina popular: 209-250. Granada: Diputación Provincial.

González Alcantud, J. A. y Rodríguez Becerra, S. (coords.). 1996. Creer y curar. La medicina popular. Granada: Diputación Provincial.

Granero Xiberta, J. 1985. "El fenómeno del curanderismo urbano”. Jano XXIX (660-H): 375-392.

Granero Xiberta, J. 1987. "El curanderismo urbano: un fenómeno en expansión”. Canelobre 11: $20-26$.

Grau García, N. 2008. "El agua y la medicina popular en el campo de Cartagena: terapia 'catártica' y purificadora". Revista Murciana de Antropología 15: 35-51.

Hammersley, M y Atkinson, P. 2009. Etnografía: métodos de investigación. Barcelona: Paidós.

Kleinman, A. 1978. "Concepts and a model for the comparison of medical systems as cultural systems". Social Science. E Medicine 12: 85-93.

Kleinman, A. y Csordas, T. 1996 "The therapeutic process", en Sargent, C. y Johnson, T. (comps.), Medical anthropology: contemporary theory and method: 3-21. Westport: Praeger Publishers.

Linares Abad, M.; Moral Gutiérrez, I. y García Ramiro, P. A. 2002. "Religión y Magia para proteger la salud del recién nacido: un microestudio en Jaén". Revista de Antropología Experimental 2: texto $\mathrm{n}^{\mathrm{o}} 27$.

Longarela, C. 2000. Las sectas destructivas y demoniacas en España. Disponible en http:// www.prolades.com/cra/adobe/sectas-sr.pdf (Consulta: 15-01-2014).

Martí Pérez, J. 1989. "Medicina popular religiosa a través dels Goigs". Arxiu d'Etnografía de Catalunya 7: 171-203.

Martínez Hernáez, A y Comelles, J. M. 1994. "La medicina popular. ¿Los límites culturales del modelo médico?». Revista de Dialectología y Tradiciones Populares XLIX (2): 109-136.

Menéndez Spina, E. L. 1992. "Modelo hegemónico, modelo alternativo subordinado, modelo de autoatención. Caracteres estructurales", en Campos Navarro, R. (comp.), La Antropología médica en México, tomo I: 97-114. México DF: Instituto Mora-Universidad Autónoma de México. 
Perdiguero Gil, E. 2004. "El fenómeno del pluralismo asistencial: una realidad por investigar". Gaceta Sanitaria 18 (Supl 1): 140-145.

Perdiguero Gil, E. 2006. "Una reflexión sobre el pluralismo médico", en Fernández Juárez, G. (coord.), Salud e interculturalidad en América Latina: antropología de la salud y crítica intercultural: 3350. Quito: Abya-Yala.

Perdiguero Gil, E. 2009. "Sobre el pluralismo asistencial", en Comelles, J. M.; Martorell, M. A. y Bernal, M. (eds.), Enfermería y Antropología: 113-135. Barcelona: Icaria.

Pitt Rivers, J. 1993. "El lugar de la gracia en la Antropología", en Pitt Rivers J. y Peristiany, J. (eds.), Honor y gracia: 280-321. Madrid: Alianza.

Prat i Carós, J. 2007. El estigma del extraño. Barcelona: Ariel.

Press, I. 1971. "The Urban Curandero". American Antbropologist 73 (3): 741-756.

Reverte Coma, J. M. 1983. "Resultados de una encuesta sobre curanderismo en España". Revista Española de Medicina Legal 10: 47-74.

Reviriego Almohalla, C. 1992. Medicina popular y espiritismo en el valle del Vinalopó: una aproximación psicosocial. Tesis doctoral, Facultad de Ciencias Políticas y Sociología. Madrid: Universidad Complutense. http://eprints.ucm.es/tesis/19911996/S/1/S1004101.pdf (Consulta: 01/01/2014)

Ritenbaugh, C. 1982. "Obesity as a culture-bound syndrome". Culture, Medicine and Psychiatry 6 (4): 347-64.

Rodríguez Molina, J. 2002. "Los 'insecticidas' en la etapa precientífica". Gazeta de Antropología 18: $1-44$.

Salazar Agulló, M.; Navarro Pellicer, S. y González Rodríguez, M. 1997. "Antropología del embarazo, parto y puerperio en la ciudad de Elche». Cultura de los Cuidados I (2): 44-53.

Samuelsen, H. y Vibeke, S. 2004. "The relevance of Foucault and Bourdieu for medical anthropology: exploring new sites". Anthropology \& Medicine 11 (1): 3-10.

Sánchez Carretero, C. 2007. "Nuestra religión, vuestra magia: los misterios dominicanos cruzan el Atlántico", en Callau Gonzalvo, S. (coord.), Culturas mágicas. Magia y simbolismo en la literatura y la cultura hispánicas: 246-259. Zaragoza: Prames.

Stoll, D. 2002a. América Latina se vuelve protestante. Las políticas del crecimiento evangélico. Edición digital http://www.nodulo.org/bib/stoll/alp.htm (Consulta 03/01/2014).

Stoll, D. 2002b. ¿Pescadores de hombres o fundadores de Imperio? El Instituto Lingüistico de Verano en América Latina. Edición digital http://www.nodulo.org/bib/stoll/ilv.htm (Consulta: 03/01/2014).

Turner, V. 1969. The ritual process. Structure and Anti-structure. Nueva York: Aldine de Gruyter.

Velasco, H. y Díaz de Rada, A. 2003. La lógica de la investigación etnográfica. Madrid: Trotta.

Fecha de recepción: 20 de enero de 2014

Fecha de aceptación: 28 de mayo de 2014 